\title{
Changes in salivary gland immunohistology and function after rituximab monotherapy in a patient with Sjögren's syndrome and associated MALT lymphoma
}

\author{
J Piipe, G W van Imhoff, A Vissink, J E van der Wal, P M Kluin, F K L Spiikervet, \\ C G M Kallenberg, H Bootsma
}

Objectives: To report the successful use of rituximab on salivary gland immunohistology and function in a patient with Siögren's syndrome (SS) and associated MALT lymphoma.

Case report: The patient was a 42 year old woman with primary SS and associated MALT lymphoma located in the parotid gland and the hard palate. Four infusions of rituximab $\left(375 \mathrm{mg} / \mathrm{m}^{2}\right)$ weekly resulted in complete remission of the lymphoma. An incision biopsy of the parotid gland before and after treatment showed improvement of the (immuno)histopathological characteristics of SS, with possible regeneration of salivary gland tissue. Furthermore, salivary analysis showed decreased inflammatory characteristics and increased stimulated salivary flow.

Discussion: Rituximab is a promising agent in the treatment of SS associated MALT lymphoma. In addition to the effect on MALT lymphoma, B cell depletion by rituximab may also attenuate the activity of SS. This case report is the first to describe the effect of rituximab on histological and sialometric/chemical characteristics of SS. The efficacy of rituximab in the treatment of SS warrants further investigation.

S jögren's syndrome (SS) is a chronic inflammatory and lymphoproliferative disease with autoimmune features. The main clinical features are progressive dryness of the mouth (xerostomia) and dryness of the eyes (keratoconjunctivitis sicca), but various systemic complications can also occur. SS is associated with high B cell activity as reflected by hypergammaglobulinaemia and the presence of several autoantibodies such as rheumatoid factor (RF), antinuclear antibodies, and anti-Ro/SSA and anti-La/SSB antibodies. Moreover, 5\% of patients develop malignant B cell lymphoma, usually located in the major salivary glands. ${ }^{1}$ Most of these lymphomas are of mucosa associated lymphoid tissue (MALT) type, and usually have an indolent course, with a 5 year overall survival of $90 \% .^{2}$

The optimal management of MALT lymphoma in patients with SS has not been clearly defined. Surgery, chemotherapy, and radiotherapy, alone or in combination, have been used. Conventional radiotherapy achieves excellent control in localised MALT lymphoma, but may cause a significant decrease of salivary gland function. ${ }^{3}$ Rituximab, a monoclonal antibody directed towards CD20 on B cells, is a promising new drug not only for the treatment of $\mathrm{B}$ cell lymphomas ${ }^{4}$ but also for various autoimmune disorders. ${ }^{6}$
Such an approach may be especially promising in the treatment of SS associated MALT lymphoma, because radiation injury to salivary gland tissue, a well known cause of progressive xerostomia, can be avoided. Furthermore, because B cells appear to be involved in the pathogenesis of SS, SS disease activity may also be attenuated and, ultimately, this may even result in amelioration of xerostomia. We present a patient with SS complicated by MALT lymphoma localised on the hard palate and in the parotid gland. The MALT lymphoma completely disappeared and a beneficial effect on histological, serological, and functional parameters of SS was seen after treatment with rituximab.

\section{CASE REPORT}

A 42 year old woman was referred to our clinic in August 2002 because of a large swelling on the hard palate with a diameter of $2 \mathrm{~cm}$. Ten years earlier, two enlarged lymph nodes in the neck had been excised elsewhere and at that time classified as benign lymphoepithelial lesions. She used no drugs. An incision biopsy from the palatal swelling and a review of the excised lymph nodes from 10 years before showed MALT lymphoma. Some small cervical and axillary lymph nodes, $5 \mathrm{~mm}$ in size, were visible on a computed tomography scan. Screening for SS showed decreased salivary gland function (unstimulated whole saliva flow of $0.06 \mathrm{ml} / \mathrm{min}$; stimulated whole saliva flow of $0.27 \mathrm{ml} / \mathrm{min}$ ) and globular sialectasia on parotid sialography. Schirmer's test was $0 / 0 \mathrm{~mm} / \mathrm{min}$ ODS and the rose bengal score was $7 / 7$ ODS. Positive tests for autoantibodies (anti-SSA and antiSSB), IgM RF at a level of $107 \mathrm{kU} / \mathrm{l}$, and an increased level of total IgG of $25.1 \mathrm{~g} / \mathrm{l}$ were found. An incision biopsy of the right parotid gland (according to Kraaijenhagen ${ }^{7}$ ) performed to confirm the diagnosis of SS, showed lymphoepithelial lesions consistent with SS, and a coexistent MALT lymphoma. The patient fulfilled the criteria for primary SS, complicated by MALT lymphoma localised on the hard palate, the parotid gland, and, most probably, in the lymph nodes as based on review histology.

She was treated weekly with a course of four infusions of rituximab $\left(375 \mathrm{mg} / \mathrm{m}^{2}\right)$, without high dose corticosteroids or other immunosuppressive drugs. No serious adverse effects were seen. The effect of rituximab treatment on MALT lymphoma as evaluated by complete clinical restaging and on SS activity as demonstrated by serological, sialometric/ chemical, and lachrymal measures, was assessed 3 months (MALT, SS) and 6 months (SS) after treatment. In addition,

Abbreviations: RF, rheumatoid factor; SS, Sjögren's syndrome 
Table 1 Serological, functional, and immunohistological measures before and after rituximab treatment

\begin{tabular}{|c|c|c|c|}
\hline & Before treatment & After 3 months & After 6 months \\
\hline \multicolumn{4}{|l|}{ Serological variables* } \\
\hline $\lg M \mathrm{RF}$ (normal $<11 \mathrm{kU} / \mathrm{l}$ ) & 107 & 74 & 110 \\
\hline $\lg G$ (normal $8.5-15 \mathrm{~g} / \mathrm{l}$ ) & 25 & 22 & 19.4 \\
\hline ESR (normal $0-10 \mathrm{~mm} / 1 \mathrm{st}$ h) & 39 & 15 & 18 \\
\hline \multicolumn{4}{|l|}{ Functional variablest } \\
\hline $\begin{array}{l}\text { UWS } / \mathrm{SWS} \text { (mean flow rate) (normal }>0.25 \mathrm{ml} / \mathrm{min} / \\
>0.75 \mathrm{ml} / \mathrm{min} \text { ) }\end{array}$ & $0.06 / 0.27$ & $0.02 / 0.38$ & $0.01 / 0.34$ \\
\hline Stimulated parotid gland function (normal $>0.3 \mathrm{ml} / \mathrm{min}$ ) & 0.07 & 0.08 & 0.07 \\
\hline Unstimulated SM/SL function (normal $>0.25 \mathrm{ml} / \mathrm{min}$ ) & 0.06 & 0.02 & 0.01 \\
\hline Stimulated SM/SL function (normal $>0.5 \mathrm{ml} / \mathrm{min}$ ) & 0.14 & 0.22 & 0.21 \\
\hline $\begin{array}{l}\text { Parotid saliva concentration } \mathrm{Na}, \mathrm{mmol} / \mathrm{l} \text { (flow rate } \\
\text { dependent normal value given between parentheses) }\end{array}$ & $22.5(2)$ & $12(3)$ & $10(2)$ \\
\hline Schirmer's test (normal $>10 \mathrm{~mm} / 5 \mathrm{~min}$ ) & 0/0 ODS & $1 / 1$ ODS & 4/4 ODS \\
\hline Rose bengal staining (normal <3.5) & $7 / 7$ ODS & $6 / 6$ ODS & $6 / 5$ ODS \\
\hline \multicolumn{4}{|l|}{$\begin{array}{l}\text { Histological and molecular analysis of parotid gland } \\
\text { tissuef }\end{array}$} \\
\hline$\%$ CD20/CD79a positive cells & $80-85$ & & \\
\hline \% CD3 positive cells & $20-15$ & 95 & \\
\hline$\% \lg A / \lg G$ plasma cells & $26 / 50$ & $58 / 26$ & \\
\hline IgH-PCR: monoclonality & Yes & No & \\
\hline
\end{tabular}

${ }^{*} \lg M$ RF, IgM rheumatoid factor; IgG, immunoglobulin G; ESR, erythrocyte sedimentation rate; fUWS, unstimulated whole saliva; SWS, $2 \%$ citric acid stimulated whole saliva; SM/SL, submandibular/sublingual gland; glandular saliva was collected in preweighed plastic tubes from both parotid glands by using modified Lashley cups, and simultaneously from the SM/SL glands by syringe aspiration from the anterior part of the floor of the mouth. Unstimulated salivary secretions were collected during 5 minutes, followed by collection of stimulated secretions ( $2 \%$ citric acid applied on the lateral border of the tongue) for 10 minutes. Sialochemical analysis was focused on the concentration of sodium in parotid saliva, as an increase in sodium is indicative of chronic sialoadenitis. ${ }^{9}$ Schirmer's test: the amount of wetting after 5 minutes is measured on a strip placed in the lower eyelid; rose bengal staining, the cornea is stained with $1 \%$ rose bengal; a high score is correlated with ocular surface damage. $\neq C D 20 / C D 79 a, B$ cell marker; CD3, T cell marker; PCR, polymerase chain reaction; molecular pattern of $B$ cell clonal expansion in parotid gland tissue.

a second incision biopsy of the right parotid gland was taken 3 months after treatment.

Complete clinical remission of the MALT lymphoma was achieved. Serological analysis showed a slight decrease of the IgG level without modification of the autoantibody status. Objective tests disclosed mild improvement of the stimulated salivary secretion and of the concentration of sodium in saliva. Also some improvement was observed in lachrymal function, although it remained at a pathological level (Schirmer's test, $<5 \mathrm{~mm}$ at $5 \mathrm{~min}$ ) (table 1). The subjective complaints showed some improvement as assessed by patient scored visual analogue scores for sicca complaints and a overall decrease of fatigue according to the Multidimensional Fatigue Inventory. ${ }^{8}$ The parotid gland biopsy after treatment showed no signs of MALT lymphoma by morphological and molecular analysis. Also, a regression was noted in the histopathological characteristics of SS. There was a decrease of the lymphoid infiltrate, now mainly consisting of T cells, with recovery of salivary gland tissue morphology. Immunohistological analysis of the infiltrate in the second biopsy specimen showed an increase in the relative percentage of IgA positive plasma cells as compared with IgG positive plasma cells (table 1, fig 1).

\section{DISCUSSION}

Anti-B cell monoclonal antibody treatment is a promising new treatment for autoimmune disorders. Initial data have shown that rituximab is efficacious and relatively safe in systemic diseases such as rheumatoid arthritis, Wegener's granulomatosis, and systemic lupus erythematosus. ${ }^{6}{ }^{10}$ Although SS is considered to be a T cell mediated disease, its systemic complications are associated with increased B cell activity. A positive effect of rituximab on clinical measures of both SS and MALT lymphoma in patients with SS has been

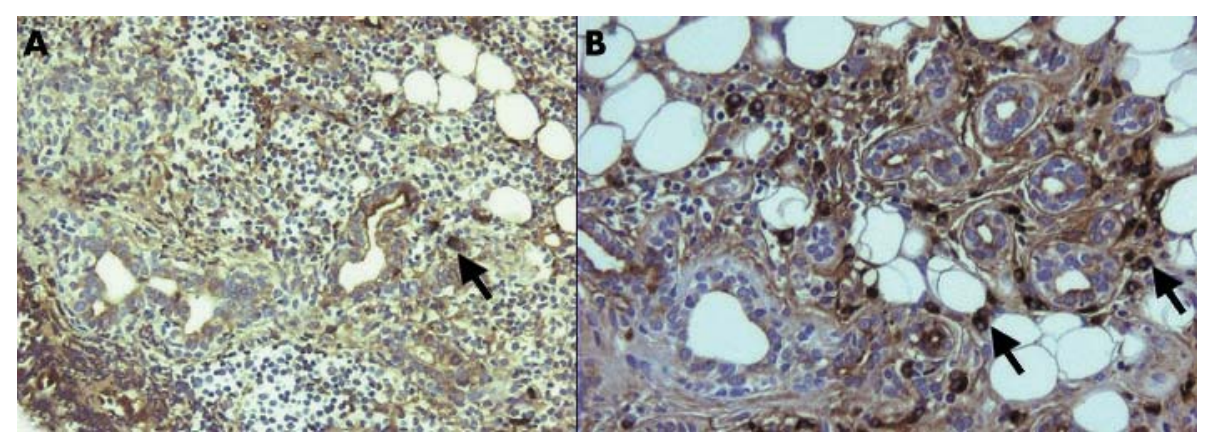

Figure 1 (A) Immunohistochemical staining for IgA positive plasma cells in parotid gland biopsy specimen before treatment, showing a few lgA positive plasma cells (arrow) and a massive infiltrate with a few ducts (magnification $\times 200$ ). (B) Immunohistochemical staining for IgA positive plasma cells in parotid gland biopsy specimen after rituximab treatment, showing less infiltrate and more salivary gland ducts, with a relative increase of lgA positive plasma cells (arrows) (magnification $\times 200$ ). 
reported in case reports, ${ }^{11}{ }^{12}$ and in a study of four patients with aggressive lymphoma and SS treated with rituximab combined with chemotherapy (R-CHOP). ${ }^{13}$ However, none of these reports examined histological variables, gland-specific salivary flow, and salivary composition.

In our patient, increased salivary output (stimulated whole saliva) was seen, mainly because of an increased stimulated secretion of the submandibular/sublingual glands. Analysis of the parotid saliva showed a decrease in sodium concentration, indicating normalisation of the sodium readsorption by the salivary gland ductal system, as in healthy subjects most of the sodium is reabsorbed from primary saliva during its transport through the ductal system. This finding is in agreement with a reduction of the inflammatory component of the secretory salivary gland cells in autoimmune sialoadenitis. ${ }^{9}$ Lachrymal gland function improved only at 6 months after treatment.

The pretreatment biopsy specimen showed less salivary gland tissue than the specimen obtained after rituximab treatment. Whether B cell depletion led to recovery or regeneration of salivary gland tissue, which is possible in this timeframe, ${ }^{14}$ or whether this observation was due to sampling error, remains uncertain. No increase in parotid gland function was seen, but longer follow up is necessary. The inflammatory infiltrate was reduced with a change in plasma cells which produce immunoglobulin. The presence of IgA positive plasma cells at $<70 \%$ or of IgM positive plasma cells at $\geqslant 10 \%$, as studied in labial salivary gland biopsy specimens, is highly specific for SS. The percentage of IgA positive plasma cells and the percentage of IgM positive plasma cells in the post-treatment biopsy specimen was still compatible with SS (58\% and $16 \%$, respectively), but there was a clear increase of the percentage of IgA positive plasma cells and a decrease of the percentage of IgM positive cells compared with the biopsy performed before treatment $(26 \%$ and $24 \%$, respectively). The decrease of IgA positive plasma cells at baseline might be the consequence of massive infiltration of lymphomatous B cells, which most commonly express surface IgM, often in combination with cytoplasmic IgM in the neoplastic plasma cells. As a result, the increase of the percentage of IgA positive plasma cells after treatment might be just a mechanical consequence of the disappearance of lymphomatous B cells. However, this assumption, at best, explains only part of the phenomena observed, as in contrast with the increase of IgA plasma cells, there was a marked concomitant decrease of IgG positive plasma cells. This change in the IgA/IgG plasma cell ratio suggests a treatment related decrease of SS activity. ${ }^{15}$ Further support for the decrease in disease activity comes from the reduced concentration of sodium in parotid saliva, which also reflects a decrease of inflammation at tissue level. Furthermore, the plasma cells in the second biopsy specimen were polyclonal, which was confirmed by polymerase chain reaction. After 6 months, IgM RF returned to the baseline value, whereas sialometric and chemical values remained stable.

As far as we know, this case report is the first to describe the effects of rituximab without other immunosuppressive drugs on histological and functional parameters in a patient with SS associated MALT lymphoma. The histological, serological, and functional components of SS in our patient improved after treatment with rituximab. IgM RF is produced by short lived plasma cells and might be a good surrogate marker for SS activity-for example, an increase of IgM RF might indicate the need for re-treatment. In addition, repeated parotid gland biopsies may offer an objective tool for evaluating treatment in patients with SS with or without associated lymphoma. A parotid gland biopsy has several advantages compared with a labial biopsy. There is more tissue available, follow up biopsies from the same gland are possible, and morbidity of an incision biopsy of the parotid gland is comparable ${ }^{16}$ or, in our hands, even less than that of a labial biopsy (unpublished data). Rituximab might be of therapeutic value in the preservation of function of the exocrine glands in patients with active SS, especially in patients with residual salivary gland function. A phase II study in patients with SS is currently underway.

\section{Authors' affiliations}

J Piipe, A Vissink, F K L Spijkervet, Department of Oral and

Maxillofacial Surgery, University Hospital Groningen, Groningen, The Netherlands

G W van Imhoff, Department of Haematology, University Hospital Groningen, Groningen, The Netherlands

J E van der Wal, P M Kluin, Department of Pathology and Laboratory Medicine, University Hospital Groningen, Groningen, The Netherlands C G M Kallenberg, Department of Clinical Immunology, University Hospital Groningen, Groningen, The Netherlands

H Bootsma, Department of Rheumatology, University Hospital Groningen, Groningen, The Netherlands

Correspondence to: Dr J Piipe, Department of Oral and Maxillofacial Surgery, University Hospital Groningen, PO Box 30.001, 9700 RB

Groningen, The Netherlands; i.pijpe@kchir.azg.nl

Accepted 27 October 2004

Published Online First 2 December 2004

\section{REFERENCES}

1 Voulgarelis M, Dafni UG, Isenberg DA, Moutsopoulos HM. Malignant lymphoma in primary Siögren's syndrome: a multicenter, retrospective clinical study by the European Concerted Action on Siögren's Syndrome. Arthritis Rheum 1999:42:1765-72.

2 Zucca E, Conconi A, Pedrinis E, Cortelazzo S, Motta T, Gospodarowicz MK, et al. Nongastric marginal zone B-cell lymphoma of mucosa-associated lymphoid tissue. Blood 2003;101:2489-95.

3 Tsang RW, Gospodarowicz MK, Pintilie M, Wells W, Hodgson DC, Sun A, et al. Localized mucosa-associated lymphoid tissue lymphoma treated with radiation therapy has excellent clinical outcome. J Clin Oncol 2003;21:4157-64.

4 Avivi I, Robinson S, Goldstone A. Clinical use of rituximab in haematological malignancies. Br J Cancer 2003;89:1389-94.

5 Conconi A, Martinelli G, Thieblemont C, Ferreri AJ, Devizzi L, Peccatori F, et al. Clinical activity of rituximab in extranodal marginal zone B-cell lymphoma of MALT type. Blood 2003;102:2741-5.

6 Silverman GJ, Weisman S. Rituximab therapy and autoimmune disorders. Arthritis Rheum 2003:48:1484-92.

7 Kraaijenhagen HA. Technique for parotid biopsy. J Oral Surg 1975;33:328.

8 Smets EM, Garssen B, Bonke B, De Haes JC. The Multidimensional Fatigue Inventory (MFI) psychometric qualities of an instrument to assess fatigue. J Psychosom Res 1995;39:315-25.

9 Mandel ID, Baurmash H. Sialochemistry in Siögren's syndrome. Oral Surg Oral Med Oral Pathol 1976;41:182-7.

10 Edwards JC, Szczepanski L, Szechinski J, Filipowicz-Sosnowska A, Emery P, Close DR, et al. Efficacy of B-cell-targeted therapy with rituximab in patients with rheumatoid arthritis. N Engl J Med 2004;350:2572-81.

11 Shih WJ, Ghesani N, Hongming Z, Alavi A, Schusper S, Mozley D. F-18 FDG positron emission tomography demonstrates resolution of non-Hodgkin's ymphoma of the parotid gland in a patient with Sjögren's syndrome: before and after anti-CD20 antibody rituximab therapy. Clin Nucl Med 2002; 27: 142-3.

12 Somer BG, Tsai DE, Downs L, Weinstein B, Schuster SJ. Improvement in Siögren's syndrome following therapy with rituximab for marginal zone lymphoma. Arthritis Rheum 2003;49:394-8.

13 Voulgarelis M, Giannouli S, Anagnostou D, Tzioufas AG. Combined therapy with rituximab plus cyclophosphamide/doxorubicin/vincristine/prednisone (CHOP) for Sjögren's syndrome-associated B-cell aggressive non-Hodgkin's lymphomas. Rheumatology (Oxford) 2004;43:1050-3.

14 Ihrler S, Blasenbreu-Vogt S, Sendelhofert A, Rossle M, Harrison JD, Lohrs U. Regeneration in chronic sialadenitis: an analysis of proliferation and apoptosis based on double immunohistochemical labelling. Virchows Arch 2004;444:356-61.

15 Zandbelt MM, van den Hoogen FH, de Wilde PC, van den Berg PJ, Schneider HG, van de Putte LB. Reversibility of histological and immunohistological abnormalities in sublabial salivary gland biopsy specimens following treatment with corticosteroids in Siögren's syndrome. Ann Rheum Dis 2001;60:511-13.

16 Marx RE, Hartman KS, Rethman KV. A prospective study comparing incisional labial to incisional parotid biopsies in the detection and confirmation of sarcoidosis, Siögren's disease, sialosis and lymphoma. J Rheumatol 1988;15:621-9. 